Review

\title{
An overview on concrete carbonation in the context of eco-efficient construction: Evaluation, use of SCMs and/or RAC
}

\author{
F. Pacheco Torgal ${ }^{\mathrm{a}, *}$, S. Miraldo ${ }^{\mathrm{b}}$, J.A. Labrincha $^{\mathrm{b}}$, J. De Brito $^{\mathrm{c}}$ \\ ${ }^{a}$ C-TAC, University of Minho, Portugal \\ ${ }^{\mathrm{b}}$ CICECO, University of Aveiro, Portugal \\ ' ICIST, DECivil-IST, Technical University of Lisbon, Portugal
}

\section{H I G H L I G H T S}

- This paper reviews current knowledge on concrete carbonation when SCMs and/or RAC are used.

- The use of the phenolphthalein indicator underestimate real concrete carbonation by as much as $100 \%$.

- The use of SCMs and and/or RAC increase the carbonation depth unless low w/b is used.

The most relevant factors that influence concrete carbonation are analysed.

\section{A R T I C L E I N F O}

\section{Article history:}

Received 15 December 2011

Received in revised form 11 April 2012

Accepted 25 April 2012

Available online $\mathrm{xxxx}$

\section{Keywords:}

Concrete carbonation

Eco-efficient construction

SCMs

RAC

\begin{abstract}
A B S T R A C T
Carbonation is a major cause of concrete structures deterioration leading to expensive maintenance and conservation operations. The eco-efficient construction agenda favours the increase of the use of supplementary cementing materials (SCMs) to reduce Portland cement's consumption and also the use of recycled aggregates concrete (RAC) in order to reduce the consumption of primary aggregates and to avoid landfill disposal of concrete waste. There is a wide range of literature published on the field of concrete carbonation related to the use of SCMs and/or RCA. However, the different conditions used by different authors limit comparison and in some cases contradictory findings are noticed. Besides, since most investigations are based on the use of the phenolphthalein indicator, which provides a poor estimate of the real concrete carbonation depth, there is a high probability that past researches could have underestimate the corrosion potential associated to concrete carbonation. This paper reviews current knowledge on concrete carbonation addressing carbonation depth's measurement, the use of SCMs and or RAC.
\end{abstract}

(c) 2012 Elsevier Ltd. All rights reserved.

\section{Contents}

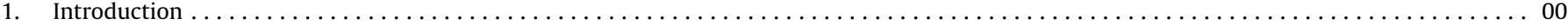

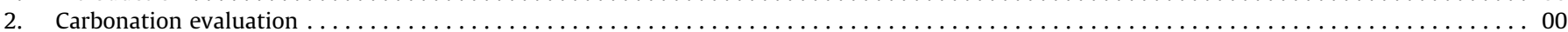

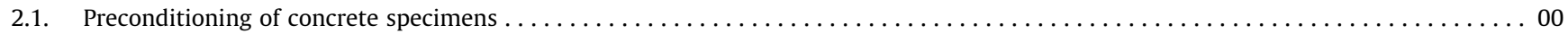

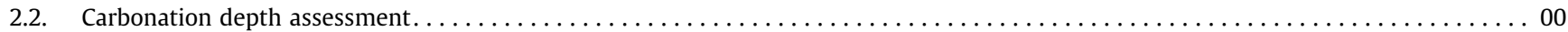

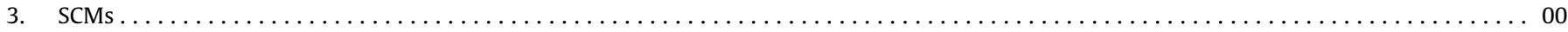

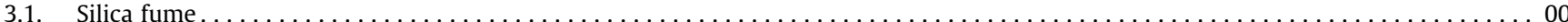

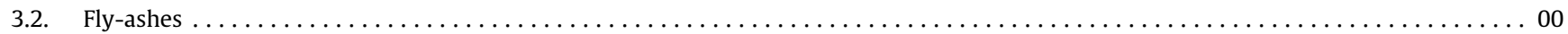

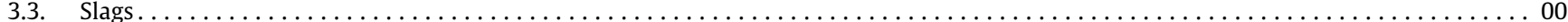

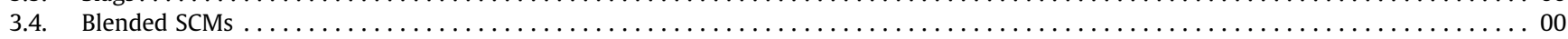

\footnotetext{
* Corresponding author.

E-mail address: torgal@civil.uminho.pt (F. Pacheco Torgal).
} 


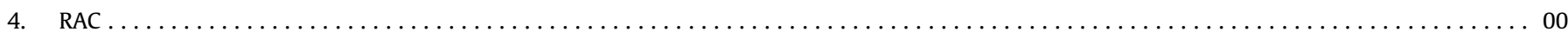

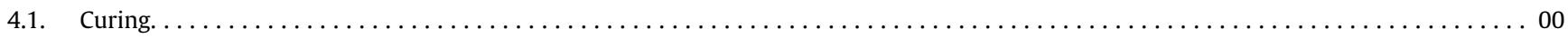

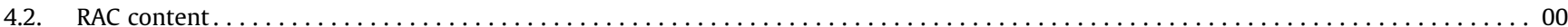

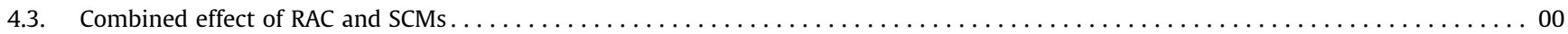

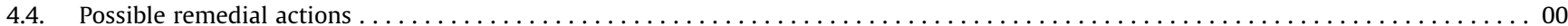

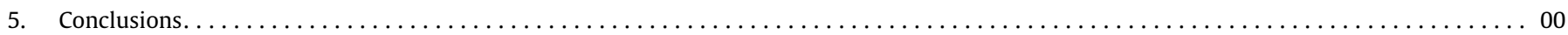

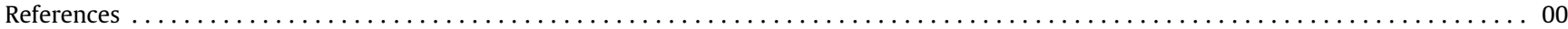

\section{Introduction}

Concrete is the most used construction material on Earth, with almost 10,000 million tons per year [1]. Projections of global demand of the main binder of concrete structures, Portland cement, show that in the next 40 years concrete production will keep on rising. Portland cement production represents $74-81 \%$ of the overall $\mathrm{CO}_{2}$ emissions of concrete, while aggregates production represents $13-20 \%$ [2]. Portland cement's $\mathrm{CO}_{2}$ emissions result from the calcination of limestone $\left(\mathrm{CaCO}_{3}\right)$ and from the combustion of fossil fuels, including the fuels required to generate electricity in power plants. To make Portland cement clinker limestone is heated with a source of silica in a kiln at temperatures well over $1350^{\circ} \mathrm{C}$. The production of one tonne of Portland cement generates 0.55 tonnes of chemical $\mathrm{CO}_{2}$ and requires an additional 0.39 tonnes of $\mathrm{CO}_{2}$ in fuel emissions for baking and grinding, accounting for a total of 0.94 tonnes of $\mathrm{CO}_{2}$ [3]. It is then no surprise that the cement industry contributes with about $7 \%$ of the total worldwide $\mathrm{CO}_{2}$ emissions [4]. Partial replacement of Portland cement by SCMs and replacement of primary aggregates by construction/industrial waste could play a key role in the eco-efficient construction [5]. Concerning the aggregates the worldwide over all consumption is about 20,000 million tonnes/year and an annual growth rate of $4.7 \%$ is expected [6], more than one third being related to concrete production. Their environmental impacts include non-renewable raw materials consumption, energy consumption and more importantly the reduction of the biodiversity at the extraction sites. Since the cost of aggregates is very dependent on the transport distances leading to extraction operations near construction sites, this multiplies the number of quarries and their biodiversity impacts. Although the use of RAC has been studied for almost 50 years [7], today structures are still made with primary aggregates. The reasons for that rely in their low cost, low deposition taxes and the lack of incentives to favour RAC. However, according to the Revised Waste framework Directive No. 2008/98/EC [8] the minimum recycling percentage for Construction and demolition (C\&D) wastes by the year 2020 should be at least $70 \%$ by weight, which means that the future will surely bring an increase in the use of RAC. Nevertheless it is crucial that these environmentally driven options do not compromise the durability of reinforced concrete structures. Less durable concrete structures require frequent maintenance and conservation operations or even its entire replacement, which is associated with the consumption of more raw materials and energy. The importance of concrete durability in the context of eco-efficient construction has been rightly put by Mora [9], when he states that increasing the durability of the concrete from 50 to 500 years would mean a reduction of its environmental impact by a factor of 10 .

Carbonation is a major cause of concrete structures deterioration. Concrete carbonation is a process by which atmospheric carbon dioxide reacts with the cement hydration products to form calcium carbonate. The importance of this phenomenon is related to the fact that it reduces the alkalinity of the concrete to a pH near 8 . Since the steel passivation layer, an iron oxide layer that protects the steel from corrosion, needs a pH between 12 and 14 (Hobbs [10] suggested that 9.5 is the $\mathrm{pH}$ threshold value for depassivation), the carbonation phenomenon can be responsible for the steel depassi- vation thus leading to corrosion. After entering in concrete $\mathrm{CO}_{2}$ will first react with calcium hydroxide available in the pore solution and then with CSH after the calcium hydroxide has been depleted [11]. The carbonation rate is controlled by the ingress of $\mathrm{CO}_{2}$ into the concrete pore system by diffusion which in turn is influenced by the relative humidity of concrete. The diffusion of $\mathrm{CO}_{2}$ is actually $10^{4}$ higher in air than in water [12]. For a low relative humidity (RH less than $50 \%$ ) the diffusion of $\mathrm{CO}_{2}$ into concrete is high but there is not enough water in the pores to generate carbonation. For a high $\mathrm{HR}$ the diffusion of $\mathrm{CO}_{2}$ is very low also reducing the carbonation rate $[13,14]$. That is why the majority of the researches on concrete carbonation use HR between $50 \%$ and $70 \%$. Previous investigations have shown that concrete carbonation is influenced by several parameters. For instance in a concrete with a water binder ratio $\mathrm{w} / \mathrm{b}=0.6$ a carbonation depth of $15 \mathrm{~mm}$ can be achieved after 15 years, but if the concrete has a lower $\mathrm{w} / \mathrm{b}=0.45$, the same carbonation depth will take 100 years to reach [15]. Wasserman et al. [16] found that for a given $\mathrm{w} / \mathrm{b}$ the carbonation was independent of binder content $\left(160-200 \mathrm{~kg} / \mathrm{m}^{3}\right)$, and this was explained in terms of two competing processes, of reduction in penetration and reduction in $\mathrm{CO}_{2}$ binding at lower cement contents. Other authors tried to correlate this mechanism with different concrete properties. Tam et al. [17] cited an extensive survey by Brown [18] that found that carbonation depths correlated well with concrete quality. She argues that the factors that increase concrete permeability can increase the carbonation rate. Atis [19] reported the existence of a strong correlation $\left(R^{2}=0.9\right)$ between carbonation depth and compressive strength for fly-ash concrete. Muntean and Bohm [20] stated that carbonation is strongly dependent on the degree of porosity, which is "the path for carbon dioxide and water to transport in concrete". However, this is in contradiction with the findings of Schutter and Audenaert [21] who found no correlation between carbonation rate and porosity. Roziere et al. [22] studied the possible correlations between porosity, chloride diffusivity, gas permeability and carbonation rate confirming there is no correlation between them. Those authors mention that porosity, chloride diffusivity and gas permeability deal with properties of the porous net of concrete, but they do not take into account chemical reactivity of binder and carbonatable content. The same authors confirmed the findings of Assie et al. [23] about a strong correlation between carbonation rate and chloride diffusivity, for concrete mixes with the same initial $\mathrm{CaO}$ content. These findings highlight the need of review efforts that try to address the gaps and the contradictions already detected in this field, so they may help to focus future investigations.

\section{Carbonation evaluation}

\subsection{Preconditioning of concrete specimens}

Table 1 shows that different researches used different preconditioning conditions in their tests. The $\mathrm{CO}_{2}$ concentration seems to be the most concerning parameter. Very few authors used outdoor atmosphere exposure and very few used the so called normal $\mathrm{CO}_{2}$ concentration $(0.03 \%)$ while the majority of the authors used high and very high $\mathrm{CO}_{2}$ concentration. Dhir et al. [24] mentioned that a comparison between a $0.035 \% \mathrm{CO}_{2}$ concentration and accelerated 
Table 1

Preconditioning of concrete specimens.

\begin{tabular}{|c|c|c|c|c|}
\hline \multirow[t]{2}{*}{ Reference } & \multirow[t]{2}{*}{ Initial curing conditions } & \multicolumn{3}{|c|}{ Carbonation chamber } \\
\hline & & Temp. $\left({ }^{\circ} \mathrm{C}\right)$ & $\mathrm{RH}(\%)$ & $\mathrm{CO}_{2}$ concentration $(\%)$ \\
\hline$[52]$ & 1 month laboratory conditions & 25 & 61 & 3 \\
\hline [60] & & 20 & 65 & 0.03 \\
\hline [62] & & 40 & 70 & 10 \\
\hline [19] & & 20 & 65 & 5 \\
\hline [61] & & 30 & 60 & 5 \\
\hline [53] & & 20 & 65 & 4 \\
\hline [32] & 28 days water cured & 23 & 70 & 20 \\
\hline [46] & 28 days water cured & 40 & 55 & 4 \\
\hline [33] & 3 month water cured & 20 & 53 & 45 \\
\hline [50] & 28 days water cured & \multicolumn{3}{|c|}{ Exposed to the outdoor atmosphere during 12 months } \\
\hline [54] & 28 days in a moisture chamber & & 55 & 40 \\
\hline \multirow[t]{2}{*}[24]{} & & 20 & 65 & 0.035 \\
\hline & & 20 & 65 & 4 \\
\hline$[42]$ & 28 days in a moisture chamber & & & $\geqslant 50$ \\
\hline [16] & & 30 & 50 & 5 \\
\hline [76] & 28-day curing period & 23 & 60 & 3 \\
\hline$[22]$ & 28 days water cured & 20 & 65 & 50 \\
\hline [55] & 90 days curing & 20 & 70 & 20 \\
\hline [48] & 28-day curing period & 23 & 70 & 0.03 \\
\hline [80] & $100 \%$ RH during 7 days plus 14 days in laboratory conditions & 30 & 60 & 10 \\
\hline [74] & & \multicolumn{3}{|c|}{ Exposed to an urban industrial natural environment } \\
\hline [64] & Cured in water for 63 days & & 70 & 1 \\
\hline [25] & 28 days water curing plus 14 days cured in dry air & 20 & 65 & 3 \\
\hline [72] & 63 days plus 16 days at $25^{\circ} \mathrm{C}$ and of $65 \% \mathrm{RH}$ & 21 & 65 & 6 \\
\hline [47] & 26 days curing & 20 & 70 & 20 \\
\hline
\end{tabular}

test ( $4 \%$ concentration) gave good agreement thus suggesting that the accelerated test method can provide an indication of likely long term concrete carbonation resistance. Limbachiya et al. [25] used accelerated carbonation tests $\left(3.5 \% \mathrm{CO}_{2}\right)$, stating that " 1 week-time exposure of concrete specimen in the carbonation chamber is somewhat equivalent to 12 months exposition under natural environment". These statements seem to forget that non-uniform $\mathrm{CO}_{2}$ concentration exists and that it is not stable over time. According to Tam et al. [17] small carbon dioxide concentrations are associated to rural air where $\mathrm{CO}_{2}$ content is about $0.03 \%$. In non-ventilated laboratory, the concentration of $\mathrm{CO}_{2}$ may rise to above $0.1 \%$. In large cities, it is about $0.3 \%$ and in some exceptional cases, it can increase to $1 \%$. Conciatori et al. [26] refers to the following carbon dioxide concentrations, land $(0.015 \%)$, town centre $(0.036 \%)$ and industrial area $(0.045 \%)$. However, Yoon et al. [27] stated that $\mathrm{CO}_{2}$ concentration in the atmosphere is increasing by $0.5 \%$ per year, and that the conditions over metropolitan areas are even more critical. Furthermore, it remains to be investigated how high $\mathrm{CO}_{2}$ concentrations influence microstructure of the cement hydration products.

\subsection{Carbonation depth assessment}

The majority of research works on concrete carbonation use a phenolphthalein indicator to assess carbonation depth. This involves spraying concrete broken faces after flexural strength tests with $1 \%$ phenolphthalein in $70 \%$ ethyl alcohol [28]. When the $\mathrm{pH}$ of the pore solution is less than 7.5, the degree of carbonation of the specimen is $100 \%$. When the $\mathrm{pH}$ value of the pore solution is between 7.5 and 9.0 , the degree of carbonation is $50-100 \%$. When the $\mathrm{pH}$ of the pore solution is $9.0-11.5$, the degree of carbonation is $0-50 \%$. However, when the $\mathrm{pH}$ of the pore solution exceeds 11.5, the specimen is not carbonated [29]. In the uncarbonated part of the specimen where the concrete is still highly alkaline, a purplered colour is obtained. In the carbonated part where the alkalinity of concrete is reduced, no colouration occurs. The average depth of the colourless phenolphthalein region has been measured in three points, perpendicular to the two edges of the split face, immediately after spraying the indicator and $24 \mathrm{~h}$ later. Bouikni et al. [30] used a more time-consuming procedure based on forty measurements on the eight faces of each broken prism, and with three prisms, the reported values of the depth of carbonation being the mean of 120 readings. In the meantime new methods have been developed to assess the carbonation depth in a more accurate way. Lo and Lee [31] mention that the carbonation rate constant determined by infrared (IR) spectrum analysis was $23.9 \%$ higher than that obtained by using the phenolphthalein indicator. Other authors [32] compared the carbonation depths determined from the Thermo-Gravimetric Analysis (TGA), X-ray Diffraction Analysis (XRDA) and Fourier Transform Infrared Spectroscopy (FTIR) methods, with the results obtained using the phenolphthalein indicator and found that the TGA, XRDA and FTIR results showed the depth of carbonation front was on average twice that determined with the phenolphthalein indicator (Table 2). Vilain et al. [33] compared thermo-gravimetry, chemical analysis (CA) and gamma-densimetry to assess the carbonation profiles. They mention that TGA has to be supplemented with CA to give accurate quantitative profiles. Chemical analysis allows obtaining the cement content in a part of the powder sample taken in concrete specimens and tested also by TGA. TGA-CA can be used to determine carbonation profile either in structure cores or in laboratory carbonated specimens. Gammadensimetry cannot easily and accurately quantify the $\mathrm{CO}_{2}$ content in a core of an aged concrete structure. Gamma-densimetry is recommended to monitor laboratory accelerated tests. Tam et al. [17] used the Fourier transform of infrared spectroscopy (FT-IR) to compare the carbonation depth among the samples. Five layers of cement paste around an aggregate were studied. The content of carbon monoxide $(\mathrm{CO})$ and carbon dioxide $\left(\mathrm{CO}_{2}\right)$ in each layer were

Table 2

Relationship between phenolphthalein colourless depths and carbonation front depths [32].

\begin{tabular}{|c|c|c|c|c|c|c|c|}
\hline \multirow{2}{*}{$\begin{array}{l}\text { Accelerated } \\
\text { carbonation } \\
\text { time (weeks) }\end{array}$} & \multirow{2}{*}{$\begin{array}{l}\text { Phenolphthalein } \\
\text { colourless depth } \\
(\mathrm{Xp}, \mathrm{mm})\end{array}$} & \multicolumn{3}{|c|}{$\begin{array}{l}\text { Carbonation front } \\
\text { depth }(\mathrm{XC}, \mathrm{mm})\end{array}$} & \multicolumn{3}{|c|}{$\mathrm{XC} / \mathrm{Xp}$} \\
\hline & & TGA & $\begin{array}{l}\text { X- } \\
\text { ray }\end{array}$ & FTIR & TGA & $\begin{array}{l}\text { X- } \\
\text { ray }\end{array}$ & FTIR \\
\hline 8 & 12 & 25 & 25 & 24 & 2.1 & 2.1 & 2.0 \\
\hline 16 & 17 & 35 & 35 & 35 & 2.1 & 2.1 & 2.1 \\
\hline
\end{tabular}


examined. Muteen et al. [34] proposed a moving-interface model to forecast the maximum penetration depth of gaseous $\mathrm{CO}_{2}$ in the porous concrete matrix. Bouchaala et al. [35] used Nonlinear Resonant Ultrasound Spectroscopy (NRUS) finding that a nonlinear parameter is significantly affected by the presence of carbonation. Research carried out to assess the depth of concrete carbonation show that the phenolphthalein indicator provides a poor estimate of the real concrete carbonation. This means that much of what has been previously said and done about potential corrosion safety due to concrete carbonation must now be reassessed. As a more direct consequence many concrete structures in which the uncarbonated depth was higher than the $10 \mathrm{~mm}$ safety threshold [27] could already have initiated reinforcement corrosion.

\section{SCMs}

According to Schubert [36] the action of SCMs is twofold, since they are associated to the consumption of $\mathrm{Ca}(\mathrm{OH})_{2}$ in the pozzolanic reaction which reduces the $\mathrm{pH}$ and increases the rate of carbonation, while at the same time the formation of new CSH blocks capillary pores decreasing carbonation. Park [37] found that the greater the amount of pozzolanic materials the deeper the carbonation depth becomes. This researcher stated that this phenomenon is primarily due to the reduction in the alkali content in the cementitious materials and the calcium silicate hydrate formed from the pozzolanic reaction absorbs more alkali ions, hence lowering the $\mathrm{pH}$ level in concrete [38].

\subsection{Silica fume}

Skjolsvold [39] investigated the influence of silica fume (SF) on the carbonation depth reporting that higher carbonation depths are associated with the use of SF. These results were confirmed by Grimaldi et al. [40]. Khan and Lynsdale [41] reported that SF slightly increases carbonation. Kulakowski et al. [42] report the existence of a 'critical threshold' in the carbonation behaviour of concrete with $\mathrm{SF}$, which is delimited by an interval of $\mathrm{w} / \mathrm{b}$ ratios (0.45 and 0.50$)$. Below the lower $\mathrm{w} / \mathrm{b}$ ratio limit, carbonation is determined mainly by the porosity of the cementitious matrix while the concentration of $\mathrm{Ca}(\mathrm{OH})_{2}$ and $\mathrm{pH}$ have little influence on carbonation depths at this ratio. For values above the upper $\mathrm{w} / \mathrm{b}$ ratio limit, chemical characteristics start to play a more significant role in carbonation depth and the consumption of $\mathrm{Ca}(\mathrm{OH})_{2}$ in the pozzolanic reactions caused by silica fume starts to have a detrimental effect on carbonation. According to these authors the effect of silica fume, in practice, is only detrimental for $\mathrm{w} / \mathrm{b}$ ratios above the 'critical carbonation threshold'.

\subsection{Fly-ashes}

Ho and Lewis [43] reported an increase in concrete carbonation when fly-ash (FA) is used. Kokubu and Nagataki [44] mentioned that the carbonation depths of fly-ash concrete decreased significantly with increasing strength grades of concrete. Ogha and Nagataki [45] reported that the carbonation increases with the replacement ratio of cement by fly-ash. These results are not confirmed by those obtained by Atis [19], who found that fly-ash concrete made with a 70\% replacement ratio showed higher carbonation than that of concrete with 50\% replacement and of the reference concrete for both moist and dry curing conditions. However, fly-ash concrete made with a 50\% replacement ratio showed lower or comparable carbonation than that of reference concrete for both curing conditions. The reason may be $\mathrm{w} / \mathrm{b}$ related, because the reference concrete has a $\mathrm{w} / \mathrm{b}=0.55$ and the $50 \%$ fly-ash mix has a $w / b=0.33$. Khunthongkeaw et al. [46] found that the carbonation coefficient of concrete increases with the fly ash content (above 30\%) and w/b. However, they also mention that the carbonation coefficient changes very little for less than 30\% fly-ash and does not change when a small amount $(10 \%)$ of fly-ash is used. Other authors [22] found that the curing conditions of concrete with and without fly-ash influences the carbonation depth (Fig. 1). Siddique [29] studied the carbonation of self-compacting concrete (SCC) mentioning that increasing fly-ash from $15 \%$ to $20 \%$ leads to an increase in the carbonation depth. However, a further increase in fly-ash content to $25 \%$, decreases carbonation depth. This author mentioned that carbonation depth was almost constant for mixes with $25 \%$ and $35 \%$ fly-ash and that the overall results of carbonation depth were very low as already found by Assie et al. [23]. Other authors [47] that studied SCC with fly-ash report the importance of initial curing on the carbonation depth (Fig. 2). The initial water-curing period of 7-day plus 21-day room curing at $75-85 \%$ RH leads to the lowest carbonation depth and 28-day water curing leads to the highest carbonation depth.

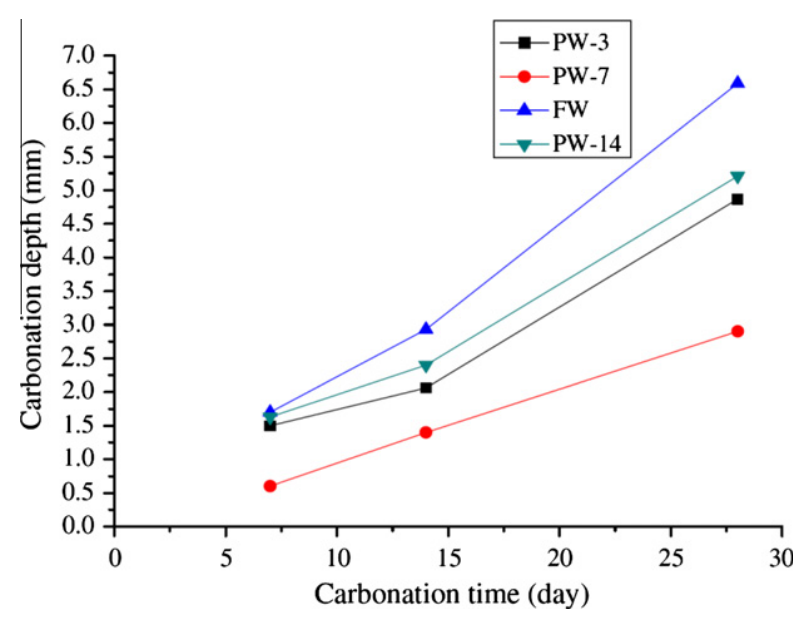

Fig. 2. The carbonation depth of SCC under different initial water-curing period [47].

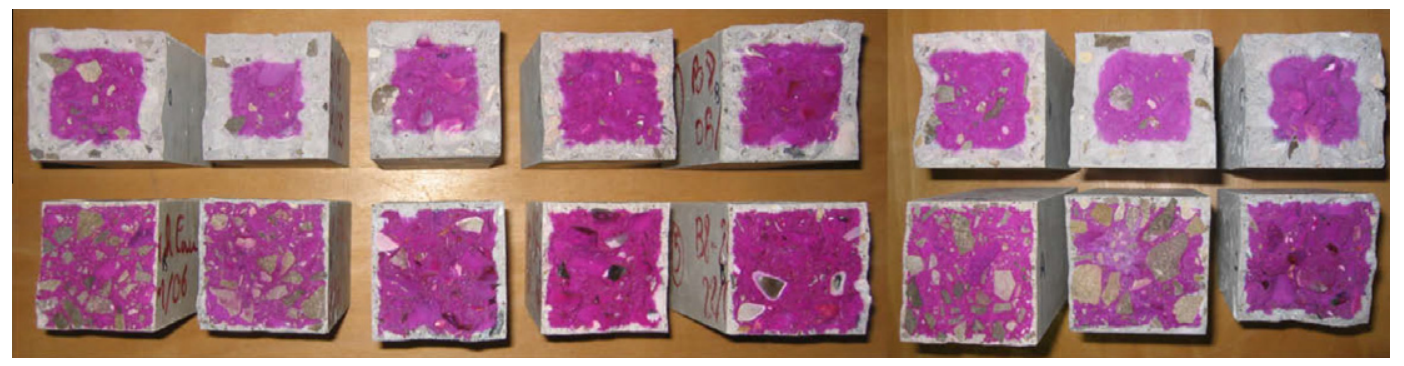

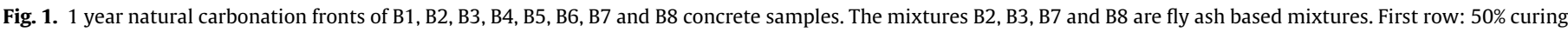
conditions. Second row: $24 \mathrm{~h}$ - water curing conditions [22]. 
According to Younsi et al. [12] when fly-ash concrete mixes are stored 28 days under water before testing (water-curing), similar carbonation depths were measured for the two mixes (30\% and $50 \%$ fly-ash), also whatever the prior oven-drying period. Watercuring has a beneficial effect on all the mixes tested. The carbonation depths are about $20-50 \%$ lower in the case of water-curing than in the case of air-curing. Chatveera and Lertwattanaruk [48] mention that the depths of carbonation of the concretes mixed with black rice husk ash (BRHA) are higher than the ordinary Portland cement (OPC) concrete. Increasing the BRHA replacement ratio (from $20 \%$ to $40 \%$ by weight of binder) tends to increase the depth of carbonation. The ratio of paste volume to void volume content of the compacted aggregates $(g)$ is an important factor for the damage of concrete. Increasing the $g$ value tends to have an adverse effect of carbonation on concrete with the higher BRHA replacement ratio due to the higher volume of cement paste. In addition, increasing the water/binder ratio tends to increase the porosity and volume of capillary pores in concrete, and significantly affect the carbonation depth.

\subsection{Slags}

Tori and Kawamura [49] noted that the depth of carbonation of concrete with mineral additions was much higher than that of the corresponding OPC concrete both at dry and wet curing conditions. In particular, 50\% slag concrete displayed higher carbonation depth than OPC concrete. A typical value of carbonation depth for slag concrete cured initially in water and exposed to dry environment for one year was $1.3 \mathrm{~mm}$, and the corresponding value for OPC concrete was $0.2 \mathrm{~mm}$. Other authors [50] mention that the blast furnace slag concrete (BFSC) showed higher carbonation depths than the corresponding OPC in all grades. For these authors the reason lies on the fact that blending of cement with mineral admixtures leads to a lowering of the $\mathrm{Ca}(\mathrm{OH})_{2}$ content in the hardened cement paste so that a smaller amount of $\mathrm{CO}_{2}$ is required to remove all the $\mathrm{Ca}(\mathrm{OH})_{2}$ by producing $\mathrm{CaCO}_{3}$. Bouikni et al. [30] mention that concrete with $65 \%$ slag replacement always showed higher carbonation penetration than concrete with $50 \%$ slag, and that water curing is clearly a major factor in reducing carbonation.

\subsection{Blended SCMs}

Byfors [51] investigated the carbonation of silica fume (SF) and pulverized fuel ash (PFA) blended cement concrete and found that the incorporation of SF has no effect on carbonation, while PFA exhibited higher rate of carbonation. Tori and Kawamura [49] noted that the carbonation depth of blended concrete increased with the water/cement ratio and decreased with the period of initial curing. Khan and Lynsdale [41] studied high performance concrete (HPC) with a $w / b=0.27$ and the use of binary and ternary blended cementitious systems based on ordinary Portland cement, PFA and SF. They observed that there was an increase in carbonation with PFA content. These authors mention that SF did not exhibit significant influence on carbonation depth. Papadakis [52] studied several SCMs (SF, low- and high-calcium fly-ash), reporting that the carbonation depth decreases as aggregate replacement by SCM's increases, and increases as cement replacement by SCMs increases. Bai et al. [53] studied PC-PFA-metakaolin (MK) concrete mixes mentioning two main trends: (i) increasing replacement of PC with PFA increases carbonation depth and (ii) systematically
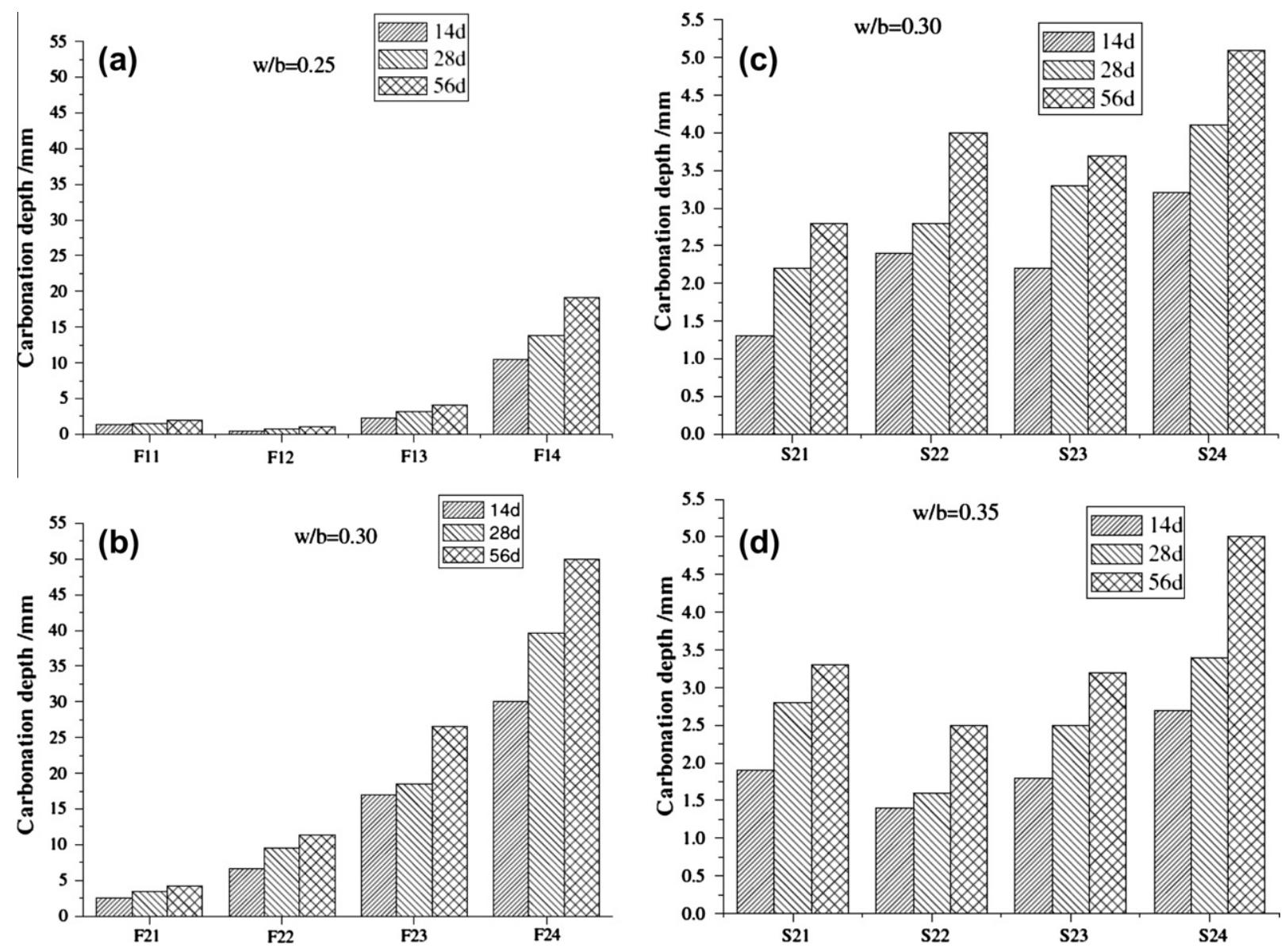

Fig. 3. Influence of FA ( $a$ and $b$ ) and GGBFS ( $c$ and d) on carbonation depth of HPC at various w/b ratios [55]. 
substituting the PFA with increasing levels of MK reduces carbonation depth. They also reported a strong correlation between carbonation depth decrease and sorptivity decrease. Dhir et al. [24] studied concrete mixes produced using combinations of Portland cement $(\mathrm{PC})$ and limestone powder finding that for $15 \%$ limestone powder there is no influence on carbonation resistance. Increasing the limestone content leads to a reduction of carbonation resistance which is higher for higher $\mathrm{w} / \mathrm{b}$ ratios. Gonen and Yazicioglu [54] reported that the carbonation depth of concrete mixes containing FA was slightly higher than that of reference concrete. In concrete mixes containing silica fume and fly-ash (SFAC) at the same time, the carbonation depth was lower compared to that of other concrete mixes, where silica fume had little effect on carbonation. These authors attribute the lower depth of carbonation in SFAC to their lower porosity; because they noticed that the porosity of the FA mix was twice that of the SFAC concrete. It is worth noticing that a similar trend also occurs for capillary water absorption. Hui-Sheng et al. [55] studied HPC with different replacement levels $(0-60 \%)$ of FA and ground granulated blast furnace slag (GGBFS). They mention that for $\mathrm{a} w / \mathrm{b}=0.30$ the carbonation depth significantly increases with FA replacement ratio (almost $50 \mathrm{~mm}$ for $w / b=0.30$ and $60 \%$ ). However, for $w / b=0.25$ an optimum effect occurs for $30 \%$ FA. They also mention that concrete mixes with GGBFS show significantly lower carbonation depth (below 5.5 $\mathrm{mm}$ ) than that of HPC with FA (Fig. 3). According to the final report of RILEM TC 205-DSC [56] on the durability of SCC, this material sometimes displays a larger carbonation depth and other times a smaller one in comparison with conventional concrete with the same amount of water and cement content, although the differences are small. They also mention that if properly cured the pore structure of SCC could be denser and less permeable. Nevertheless it seems that a slightly increased vulnerability is noticed concerning carbonation of SCC with limestone filler. Valcuende and Parra [57] studied the natural carbonation of SCC containing limestone fines noting that this material has lower carbonation depths than normal vibrated concrete due to a refinement in the pore structure provided by the limestone fines. They also report that carbonation decreases when $\mathrm{w} / \mathrm{b}$ is reduced and that for the same $\mathrm{w} / \mathrm{b}$ carbonation is lower when $45 \mathrm{R}$ cement is used instead of $32.5 \mathrm{~N}$ cement.

\section{RAC}

Larbi and Steijaert [58] mention that the depth of carbonation is greater for porous aggregates (with interconnected pores) concrete than for normal (dense) aggregate concrete. Sagoe-Crentsil et al. [59] mention a $10 \%$ increase in the carbonation rate of concrete with coarse recycled aggregates. The coarse recycled aggregates had $5.6 \%$ water absorption and were pre-saturated for 10 min. Other authors [60] found that the carbonation rate of concrete with both coarse and fine recycled aggregates is 3.2 times higher than for primary aggregate concrete. The concrete mix containing natural sand and coarse recycled aggregates showed a carbonation rate 1.8 times higher than for primary aggregates concrete. Fine and coarse recycled aggregates had a water absorption value respectively of $12 \%$ and $6 \%$ and were used pre-soaked. Katz [61] found that the depth of carbonation of the recycled concrete aggregates was 1.3-2.5 times greater than that of the reference concrete. Coarse, medium and fine recycled aggregates were used with water absorptions equal to (3\%, $9 \%$ and $11 \%$ ). According to the author the properties of aggregates made from crushed concrete and the effect of the aggregates on the new concrete (e.g. strength, modulus of elasticity,) resemble those of lightweight aggregate concrete, and similar considerations apply when dealing with this type of aggregates. Otsuki et al. [62] mention that carbonation the rate of concrete $(\mathrm{w} / \mathrm{b}=0.4)$ with coarse recycled aggregates is just slightly higher than for primary aggregates concrete. They used coarse recycled aggregates with a water absorption in a range of $3-5 \%$. According to Rao et al. [63] the increase in the carbonation depth of RAC could be attributed to the higher permeability of the recycled aggregates on account of the presence of old mortar adhering to the original aggregate, and the old interfacial transition zone (ITZ) between them. Other authors [17] found several acceptable correlations between carbonation depth and absorption, $\left(R^{2}=0.76\right)$; particle density $\left(R^{2}=0.73\right)$ and porosity $\left(R^{2}=0.77\right)$. Werle [64] reported that the carbonation depth is influenced by the porosity of the recycled aggregates. Aggregates with a porosity lower than the matrix porosity lead to a reduction of the carbonation depth.

\subsection{Curing}

Balayssac et al. [65] found that carbonated depth decreases rapidly when the curing period increases from 1 to 3 days. After 18 months, for a concrete with a cement content of $350 \mathrm{~kg} / \mathrm{m}^{3}$, increasing the curing period from 1 to 28 days halves the carbonation depth. For concrete stored for 18 months, increasing the curing period from 1 to 3 days increases the durability performance by a value of $10 \%$ for a concrete with a cement content of $300 \mathrm{~kg} / \mathrm{m}^{3}$ and $50 \%$ for a concrete with a cement content of $420 \mathrm{~kg} / \mathrm{m}^{3}$; increasing the curing period from 3 to 28 days still improves the durability performance by a value of $30 \%$ the concrete with the lowest cement content, but only by a value of $10 \%$ the concrete with the highest cement content. Bai et al. [53] mention that water-curing reduces sorptivity, which reflects a finer pore structure that will, inhibit ingress of aggressive elements into the pore system reducing carbonation. Other authors [60] found that the depth of carbonation is cut by half when concrete is cured in water. The decrease in the depth of carbonation might be partially due to the higher internal humidity content of this concrete. However, this influence would be less pronounced for concrete with recycled aggregates because of its higher porosity allowing faster water evaporation after curing. Lo and Lee [31] found that large differences in carbonation depth were recorded between water-cured and air-cured samples but the difference decreased with time. Water-cured concrete was found to have carbonated to $72 \%$ of the level reached by air-cured samples after 3 months of accelerated curing. Atis [19] showed that the longer initial curing period resulted in lower carbonation depth. The effect is more marked with moist curing. Haque et al. [66] studied lightweight aggregates mentioning that the greater the extent of initial water curing, the lesser the depth of carbonation. Lo et al. [67] found that mixes under hot water curing exhibited higher carbonation than mixes under normal curing. Lo et al. [68] stated that the carbonation depth under accelerated curing was higher than that of concrete under normal curing. The trend was more prominent for mixes with a higher $w / c$ ratio, than for the mixes, with a lower $w / c$ ratio. One of the reasons was that the samples were cured in hot water for 3 days and thereafter stored in water for normal curing for 24 days. This indicates that the initial curing period of PFA-incorporated concrete in hot water for 3 days resulted in larger inter-pores in the cement paste. Limbachiya et al. [25] mentioned that carbonation increase with $\mathrm{w} / \mathrm{b}$ and also that the water stored in the pore system of the recycled aggregates and released throughout hydration process may contribute to the carbonation process of the RAC mixes compared to the control mixes. Moreover, it is well recognized that carbonation of concrete occurs at a relative humidity from about $40-70 \%$. Due to the high water absorption of the coarse recycled aggregates, the control mixes have generally lower moisture content compared to the corresponding RAC. This may also explain the low resistance to carbonation of concretes containing coarse recycled aggregates. 


\subsection{RAC content}

The carbonation depth increases with recycled aggregates content [69]. Li [70] cites research works published in Chinese journals confirming that the recycled aggregates content has some influence on the carbonation resistance of concrete. As the recycled aggregates content increases, so does the carbonation depth. When the recycled aggregates content is $60 \%$, the carbonation depth increases as much as $62 \%$ compared to that of the reference concrete. Gomes and de Brito [71] mentioned that recycled aggregates concrete shows just a slight increase in the carbonation depth when compared to primary aggregates concrete. However, when more than $50 \%$ of the volume is replaced by recycled aggregates the carbonation depth increases about $10 \%$. Other authors [72] mentioned that the increased content of recycled aggregates, both fine and coarse, did not have much influence on the carbonation depth of concrete. However, concrete produced with recycled aggregates tends to present slightly higher rates of carbonation depth (about $5 \mathrm{~mm}$ ) than the reference concrete. Concrete mixes with $100 \%$ coarse and fine recycled aggregates present carbonation depth rates that are about $43 \%$ higher than those produced with $100 \%$ primary aggregates. The higher the $m=$ (recycled aggregate) cement) ratio and the $\mathrm{w} / \mathrm{c}$ ratio the greater the concrete carbonation depths are. Limbachiya et al. [25] mentioned that adding various proportions of coarse recycled aggregates as a partial replacement of primary aggregates has resulted in a lower resistance to carbonation, especially for the C30 and C35 concrete grades. The carbonation depth and the rate of carbonation of concrete increase when the content of recycled aggregates enhances. Evangelista and Brito [73] used only two RAC with $30 \%$ and $100 \%$ replacement of fine primary aggregates with fine recycled fine aggregates (FRAs) and obtained the following results concerning carbonation depth after 90 days in the carbonation chamber: the $30 \%$ RAC had a performance $27 \%$ better than the reference concrete's and the 100\% RAC 35\% worse. The authors considered the first result anomalous and possibly due to the limited number of specimens tested. However, they mentioned that results were compatible with the ones from the compression strength test where all the RAC mixes achieved values very similar to the one of the reference concrete. Zega and Di Maio [74] studied natural carbonation during 310 and 620 days of concrete mixes with a partial replacement (20\% and $30 \%$ ) of fine recycled aggregates (FRAs). These authors reported a similar carbonation depth for mixes with different FRA content, which they attribute to the low w/b ratio (0.41-0.43).

\subsection{Combined effect of RAC and SCMs}

Corinaldesi and Moriconi [75] mention that the carbonation depth after 1 year was $8.6 \mathrm{~mm}, 5.9 \mathrm{~mm}$ and $6.5 \mathrm{~mm}$, respectively, for the reference mix (REF), recycled aggregates mix (REC) and recycled aggregates plus fly-ash mix (REC + FA). They concluded that, for mixes prepared with lower water/cement ratio and due to the refinement of the pore system, carbonation did not present evidence of risks for reinforcement corrosion. This is due to the very low permeability of these mixes, even if porous aggregates, such as recycled aggregates, were used. Abbas et al. [76] found that mixes with fly-ash had the greatest carbonation depth throughout the 140-days of exposure. This behaviour can be attributed to the pozzolanic action of the SCMs, which consume $\mathrm{Ca}(\mathrm{OH})_{2}$ and consequently lower the alkalinity of concrete. The carbonation coefficients of specimens with fly-ash were the largest and were almost twice the values of specimens without SCMs. The carbonation depths of RAC with and without SCMs fall in the expected range for structural-grade conventional concrete. RAC specimens without SCMs showed the lowest level of carbonation, followed by specimens containing blast furnace slag and fly-ash, respectively. Specimens with high cement content were found to have high resistance to carbonation. Other authors [77] mentioned that the incorporation of coarse recycled aggregates and fly-ash significantly cut down the concrete's carbonation resistance, which is related with the replacement rate; the content of $\mathrm{Ca}(\mathrm{OH})_{2}$ in the RAC decreased and there are also obvious interface transition zones between the coarse recycled aggregate and the new paste. There are obvious cracks and large voids before the RAC is loaded, which leads directly to lower carbonation resistance. According to Tian et al. [78] the use of FA as a substitute for cement decreased the carbonation depth of the RAC. It is observed that the largest influence on the depth of carbonation of the RAC comes from the $w / b$ ratio, which means that the carbonation age and FA content have a lower effect. Zhu et al. [79] studied the carbonation resistance in concrete mixes with several replacement levels of primary aggregates by both fine and coarse recycled aggregates. Several replacement levels of fly-ash and slag were also used. They found that SCMs mitigate carbonation increase caused by recycled aggregates. Sim and Park [80] studied the combined effect of fly-ash addition and the recycled aggregates incorporation by volume replacement. The overall carbonation depths were lower at $60 \%$ and $100 \%$ replacement ratio than at $0 \%$ and $30 \%$ (Fig. 4 ). They mentioned that this unexpected result may in part be due to the error in the experiments or the nature of the recycled aggregates that is largely dependent on the properties of the original concrete. It can be concluded that the RAC even with some addition of fly-ash can provide sufficient resistance to carbonation based on the measured carbonation depths which were mostly below $10 \mathrm{~mm}$. Other authors [25] mentioned that for a given design strength, the carbonation depth of all the fly-ash concrete mixes was quite greater than the one of the OPC concrete mixes. They also mention that combining fly ash with coarse recycled aggregates in concrete may enhance the long term resistance to carbonation. A reliable linear relationship between the carbonation coefficient and time of exposure as well as between the carbonation coefficient and compressive strength was observed. As expected, the higher the compressive strength of concrete, the lower is the carbonation coefficient was.

\subsection{Possible remedial actions}

Several authors suggested some remedial actions to minimize concrete carbonation when recycled aggregates are used. Shayan and $\mathrm{Xu}$ [81] studied four treatments that were applied to the RAC as follows: 1(a)-Concentrated sodium silicate solution, designated N42 solution; 1(b)-Diluted (50\%) N42 solution; 2-Diluted N42 solution and lime; 3-Diluted N42 solution and silica fume; and 4. Diluted N42 solution, silica fume, and lime. These treatments were initially applied to coarse RCA for the assessment of their effect on the RCA surface features.

They mentioned that the mixes with no chemical treatment had lower carbonation depths. They also mentioned that since carbonation depth is a function of the amount of water in concrete, lower carbonation depths could result from high humidity or wet concrete. Tsujino et al. [82] used an oil and silane-type surface improving agents (Table 3 ) that increases the resistance to carbonation both for $w / b=0.4$ and 0.6. Otsuki et al. [62] suggested a double mixing method to improve carbonation resistance. In the double mixing method, the addition of water is divided into two stages. The first portion of water is added into the mixer for $30 \mathrm{~s}$ after fine and coarse aggregates have been mixed for $30 \mathrm{~s}$. The mixing is then stopped while the cement is being added into the mixer. This is followed by $60 \mathrm{~s}$ of mixing by machine and $60 \mathrm{~s}$ of mixing by hand. After that, the final portion of water is added for $30 \mathrm{~s}$ and the mixing continues for the last $90 \mathrm{~s}$. This method is devised to coat RCA 

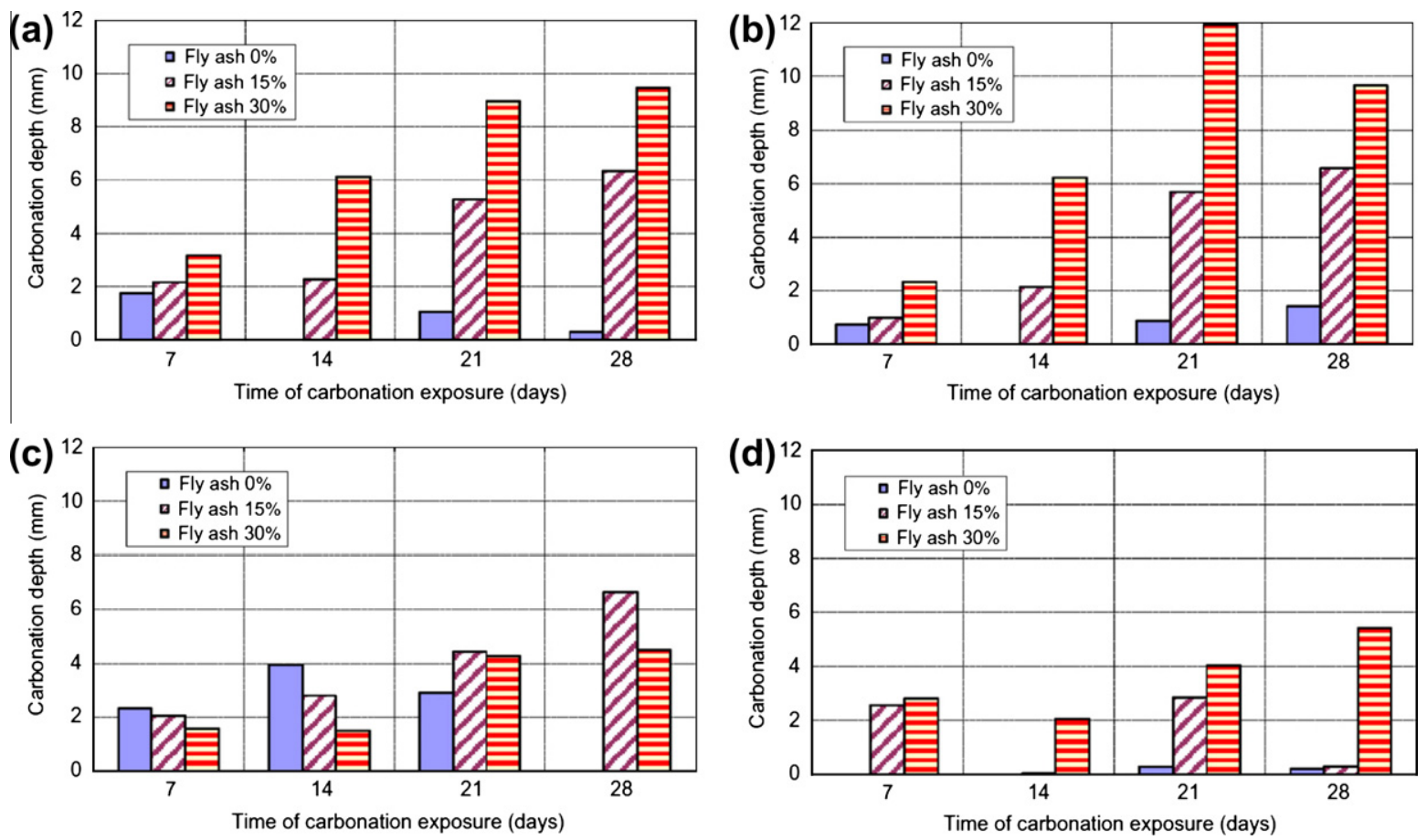

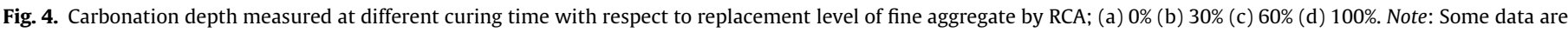
missing due to lack of specimen [80].

Table 3

Types of surface improving agents [82].

\begin{tabular}{|c|c|c|c|c|}
\hline Type & \multicolumn{2}{|l|}{ Oli $(0)$} & \multicolumn{2}{|l|}{ Silane (S) } \\
\hline Application & \multicolumn{2}{|c|}{ Release agent used in wooden form } & \multicolumn{2}{|c|}{ Water-repellent agent with permeability to the concrete surface } \\
\hline Main constituent & $\begin{array}{l}\text { Mineral oil (paraffin) } \\
\text { Emulsifying agent } \\
\text { Lanolin fatty acid salt }\end{array}$ & $\begin{array}{l}85-95 \% \\
1-5 \% \\
1-5 \%\end{array}$ & $\begin{array}{l}\text { Silicon analogue } \\
\text { Emulsifying agent } \\
\text { Water }\end{array}$ & $\begin{array}{l}28-32 \% \\
\text { Minute quantity } \\
68-72 \%\end{array}$ \\
\hline State & Emulsion & & Emulsion & \\
\hline
\end{tabular}

with mortar of a lower water-binder ratio than the rest of mortar matrix. Jianzhuang et al. [83] suggested the use of a maximum volume of coarse recycled aggregates and the use of recycled aggregates from concrete with minimum strength class as a way to increase resistance to carbonation.

\section{Conclusions}

The bibliographic survey here reported reveals how complex the carbonation process is, especially when variable formulations and distinct preparation and curing conditions are used. As a consequence, distinct controversial findings are reported. As a general guide we may conclude the following:

The carbonation is a chemical reaction whose main reactant, in cementitious systems, is the Portlandite. The extent and rate (kinetic) of the process are also affected by physical parameters of the masses (porosity/permeability) and by the practical curing and exposure conditions (e.g. $\mathrm{CO}_{2}$ concentration in the environment, humidity, temperature, etc.).

In principle we should expect a higher incidence/extent of the carbonation phenomenon in mixtures that have or generate more Portlandite, i.e., those that are richer in Portland cement, whose hydration/hardening process generates $\mathrm{Ca}(\mathrm{OH})_{2}$ as a byproduct. So, when SCMs are used to (partially) replace the cement fraction, the carbonation should be minimized (less amount of reactant).
This tendency was not always reported in the consulted references, because it is not clear if the SCM was always introduced as direct cement substitute or simply added to the all mass.

The use of SCMs, especially when have pozzolanic characteristics, should also contribute to reduce the carbonation, since the pozzolanic reaction will consume $\mathrm{Ca}(\mathrm{OH})_{2}$. However, the course of the carbonation might be seriously determined by physical aspects. For instance when the SCMs is used to partially replace the cement fraction, the extent of hydration tends to decrease. As a result the permeability and sorptivity of the bodies increase and the ingress of atmospheric $\mathrm{CO}_{2}$ is facilitated.

Apart the hydraulic differences, the compactness of a cementitious matrix also depends on the particle size distribution of the constituents and on the existence of intrinsic porosity (e.g. lightweight aggregates). Amongst the distinct studies, there are certainly relevant differences in these physical and morphological parameters that might generate contradictory findings. The compaction degree also depends, often decisively, on the amount of water $(\mathrm{w} / \mathrm{b}$ or $\mathrm{w} / \mathrm{c}$ ratios) used to prepare the material. When in excess to the amount strictly consumed in the formation of hydrates, the free portion will be removed and voids or pores will appear on the cured samples. Storage conditions will naturally play an important role in the extent of water removal: curing under water or in a dry environment, temperature, etc.

In addition to the vol.\% or wt.\% pores in the mass, their shape and interconnectivity will be also relevant in determining the per- 
meability of the material and, therefore, the carbonation extent. Most consulted works did not reveal porosimetry analysis, in order to account with relevant morphological details.

\section{References}

[1] Glavind M. Sustainability of cement, concrete and cement replacement materials in construction. In: Khatib editor, Sustainability of Construction Materials. Wood Head Publishing in Materials. Cambridge, UK: Great Abington; 2009. p. 120-47.

[2] Flower D, Sanjayan J. Greenhouse gas emissions due to concrete manufacture. Int J Life Cycle Assess 2007;12:282-8.

[3] Gartner E. Industrially interesting approaches to low- $\mathrm{CO}_{2}$ cements. Cem Concr Res 2004;34:1489-98.

[4] Ali M, Saidur R, Hossain S. A review on emission analysis in cement industries. Renew Sustain Energy Rev 2011;15:2252-61.

[5] Meyer C. The greening of the concrete industry. Cem Concr Compos 2009;31:601-5.

[6] Bleischwitz R, Bahn-Walkowiak B. Aggregates and construction markets in Europe: towards a sectorial action plan on sustainable resource management. Miner Eng 2011;22:159-76.

[7] Malhotra V. Recycled concrete - a new aggregate. Can J Civ Eng 1978;5:42-52.

[8] European Parliament, Directive 2008/98/EC of the European Parliament and of the council of 19 November 2008 on waste and repealing certain directives (text with EEA relevance). Official Journal of the European Union, vol. 312. p. 3-30.

[9] Mora E. Life cycle, sustainability and the transcendent quality of building materials. Build Environ 2007;42:1329-34.

[10] Hobbs DW. Carbonation of concrete in PFA. Mag Concr Res 1988;40:69-78.

[11] Peter M, Munteen A, Meier S, Bohm M. Competition of several carbonation reactions in concrete: a parametric study. Cem Concr Res 2008:38:1385-93.

[12] Younsi A, Turcry P, Rozière E, Aït-Mokhtar A, Loukili A. Performance-based design and carbonation of concrete with high fly ash content. Cem Concr Compos 2011;33:993-1000.

[13] Papadakis VG, Vayenas CG, Fardis MN. Experimental investigation and mathematical modeling of the concrete carbonation problem. Chem Eng Sci 1991;46:1333-8.

[14] Papadakis VG, Vayenas CG, Fardis MN. Hydration and carbonation of pozzolanic cements. ACI Mater J 1992;89:119-30.

[15] Wiering P. Long time studies on the carbonation of concrete under normal outdoor exposure. In: RILEM symposium on durability of concrete under normal outdoor exposure. Hannover; 1984.

[16] Wassermann R, Katz A, Bentur A. Minimum cement content requirements: a must or a myth? Mater Struct 2009;42:973-82.

[17] Tam V, Wang K, Tam C. Assessing relationships among properties of demolished concrete, recycled aggregate and recycled aggregate concrete using regression analysis. J Hazard Mater 2008;152:703-14.

[18] Brown JH. The effect of exposure and concrete quality: field survey results from some 400 structures. In: The 5th international conference on the durability of materials and components. Bringhton; 1991. p. 249-259.

[19] Atis C. Accelerated carbonation and testing of concrete made with fly ash. Constr Build Mater 2003;17:147-52.

[20] Muntean A, Böhm MA. Moving-boundary problem for concrete carbonation: global existence and uniqueness of weak solutions. J Math Anal Appl 2009;350:234-51.

[21] Schutter G, Audenaert K. Evaluation of water absorption of concrete as a measure for resistance against carbonation and chloride migration. Mater Struct 2004;37:591-6.

[22] Roziere E, Loukili A, Cussigh F. A performance based approach for durability of concrete exposed to carbonation. Constr Build Mater 2009;23:190-9.

[23] Assie S, Escadeillas G, Waller V. Estimates of self-compacting concrete 'potential' durability. Constr Build Mater 2007;21:1909-17.

[24] Dhir R, Limbachiya M, McCarthy M, Chaipanich A. Evaluation of Portland limestone cements for use in concrete construction. Mater Struct 2007;40:459-73.

[25] Limbachiya M, Meddah MS, Ouchagour Y. Use of recycled concrete aggregate in fly-ash concrete. Constr Build Mater 2012;27:439-49.

[26] Conciatori D, Laferrière F, Brühwiler E. Comprehensive modeling of chloride ion and water ingress into concrete considering thermal and carbonation state for real climate. Cem Concr Res 2010;40:109-18.

[27] Yoon I-S, Copuroglu O, Park K-B. Effect of global climatic change on carbonation progress of concrete. Atmos Environ 2007;41:7274-85.

[28] RILEM. CPC-18 measurement of hardened concrete carbonation depth. Mater Struct 1988;21(6):453-5.

[29] Siddique R. Properties of self-compacting concrete containing class F fly ash. Mater Des 2011;32:1501-7.

[30] Bouikni A, Swamy R, Bali A. Durability properties of concrete containing $50 \%$ and 65\% slag. Constr Build Mater 2009;23:2836-45.

[31] Lo Y, Lee H. Curing effects on carbonation of concrete using a phenolphthalein indicator and Fourier-transform infrared spectroscopy. Build Environ 2002;37:507-14.

[32] Chang C-F, Chen J-W. The experimental investigation of concrete carbonation depth. Cem Concr Res 2006;36:1760-7.
[33] Villain J, Thiery M, Platret G. Measurement methods of carbonation profiles in concrete: thermogravimetry, chemical analysis and gammadensimetry. Cem Concr Res 2007;37:1182-92.

[34] Muteen A, Bohm M, Kropp J. Moving carbonation fronts in concrete: a movingsharp-interface approach. Chem Eng Sci 2011:66:538-47.

[35] Bouchaala F, Payan C, Garnier V, Balayssac J. Carbonation assessment in concrete by nonlinear ultrasound. Cem Concr Res 2011;41:557-9.

[36] Schubert P. Carbonation behaviour of mortars and concrete made with fly ash. ACI Special Publications SP-100; 1987. p. 1945-62.

[37] Park GK. Durability and carbonation of concrete. Mag Korean Concr Inst 1995;7:74-81.

[38] Mindess S, Young JF, Darwin D. Concrete. 2nd ed. New Jersey, USA: Prentice Hall; 2002.

[39] Skjolsvold O. Carbonation depths of concrete with and with out condensed silica fume. ACI Special Publications SP-91; 1986. p. 1031-48.

[40] Grimaldi G, Carpio J, Raharinaivo A. Effect of silica fume on carbonation and chloride penetration in mortars. In: Mohammed Alasali, editor. Third CANMET/ACI international conference on fly ash, silica fume, slag and natural pozzolans in concrete; 1989. p. 320-34.

[41] Khan M, Lynsdale C. Strength, permeability, and carbonation of highperformance concrete. Cem Concr Res 2002;32:123-31.

[42] Kulakowski M, Pereira F, Dal Molin D. Carbonation-induced reinforcement corrosion in silica fume concrete. Constr Build Mater 2009;23:1189-95.

[43] Ho D, Lewis R. Carbonation of concrete incorporating fly ash or a chemical admixture. In: First international conference on the use of fly ash, silica fume, slag and other mineral by-products in concrete, vol. SP-79. Montebello, Canada; 1983. p. 333-46.

[44] Kokubu M, Nagataki S. Carbonation of concrete with fly ash and corrosion of reinforcements in 20 years tests. In: Third international conference on fly ash, silica fume, slag and natural pozzolans in concrete, vol. SP-114. Trondheim, Norway, ACI; 1989. p. 315-29.

[45] Ogha H, Nagataki S. Prediction of carbonation depth of concrete with fly ash. In: Third international conference on fly ash, silica fume, slag and natural pozzolans in concrete, vol. SP-114. Trodheim, Norway; 1989. p. 275-294.

[46] Khunthongkeaw K, Tangtermsirikul S, Leelawat T. A study on carbonation depth prediction for fly ash concrete. Constr Build Mater 2006;20:744-53.

[47] Zhao H, Sun W, Wu X, Gao B. Effect of initial water-curing period and curing condition on the properties of self-compacting concrete. Mater Des 2012;35:194-200.

[48] Chatveera B, Lertwattanaruk P. Durability of conventional concretes containing black rice husk ash. J Environ Manage 2011;92:59-66.

[49] Torii K, Kawamura M. Pore structure and chloride permeability of concretes containing fly ash, blast furnace slag and silica fume. Fly ash, silica fume, slag and natural pozzolans in concrete, vols. SP-132 and 1. Detroit: American Concrete Institute; 1992. p. 135-50.

[50] Dinakar P, Babu K, Santhanam M. Corrosion behaviour of blended cements in low and medium strength concretes. Cem Concr Compos 2007;29:136-45.

[51] Byfors K. Carbonation of concrete with silica fume and fly ash. J Nordic Concr Res 1985;4:26-35.

[52] Papadakis V. Effect of supplementary cementing materials on concrete resistance against carbonation and chloride ingress. Cem Concr Res 2000;30:291-9.

[53] Bai J, Wild S, Sabir B. Sorptivity and strength of air-cured and water-cured PCPFA-MK concrete and the influence of binder composition on carbonation depth. Cem Concr Res 2002;32:1813-21.

[54] Gonen T, Yazicioglu S. The influence of mineral admixtures on the short and long-term performance of concrete. Build Environ 2007;42:3080-5.

[55] Hui-Sheng S, Bi-Wan X, Xiao-Chen Z. Influence of mineral admixtures on compressive strength, gas permeability and carbonation of high performance concrete. Constr Build Mater 2009;23:1980-5.

[56] De Schuter G, Audenaert K. Final report of RILEM TC 205-DSC: durability of self-compacting concrete. Mater Struct 2008;41:225-33.

[57] Valcuende M, Parra C. Natural carbonation of self-compacting concretes. Constr Build Mater 2010;24:848-53.

[58] Larbi J, Steijaert P. Microstructure of concretes containing artificial aggregates and recycled aggregates. In: Gourmans J, Van der Sloot H, Aalbers T. editors. Environmental Aspects of Construction with Waste Materials; 1994. p. 87788.

[59] Sagoe-Crentsil K, Brown T, Taylor A. Performance of concrete made with commercially produced coarse recycled concrete aggregate. Cem Concr Res 2003;31:707-12.

[60] Buyle-Bodin F, Hadjieva-Zaharieva R. Influence of industrially produced recycled aggregates on flow properties of concrete. Mater Struct 2002;35:504-9.

[61] Katz A. Properties of concrete made with recycled aggregate from partially hydrated old concrete. Cem Concr Res 2003;33:703-11.

[62] Otsuki N, Miyazato S, Yodsudjai W. Influence of recycled aggregate on interfacial transition zone, strength, chloride penetration and carbonation of concrete. J Mater Civ Eng 2003:443-51.

[63] Rao et al. Use of aggregates from recycled construction and demolition waste in concrete. Resour Conserv Recycl 2007;50:71-81.

[64] Werle A, Kazmierczak C, Kulakowski M. Carbonation of concrete with recycled concrete aggregates. Ambiente Construído, Porto Alegre 2011;11(2):213-28 [in Portuguese].

[65] Balayssac J, Detriche H, Grandet J. Effects of curing upon carbonation of concrete. Constr Build Mater 1995;9:91-5. 
[66] Haque M, Al-Khait H, Kayali O. Long-term strength and durability parameters of lightweight concrete in hot regime: importance of initial curing. Build Environ 2007;42:3086-92.

[67] Lo T, Tang W, Nadeem A. Comparison of carbonation of lightweight concrete with normal weight concrete at similar strength levels. Constr Build Mater 2008;22:1648-55

[68] Lo T, Nadeem A, Tang W, Yu P. The effect of high temperature curing on the strength and carbonation of pozzolanic structural lightweight concretes. Constr Build Mater 2009;23:1306-10.

[69] Levy, Helene. Durability of recycled aggregates concrete: a safe way to sustainable development. Cem Concr Res 2004;34:1975-80.

[70] Li X. Recycling and reuse of waste concrete in China: Part I. Material behaviour of recycled aggregate concrete. Resour Conserva Recycl 2008;53:36-44.

[71] Gomes M, de Brito J. Structural concrete with incorporation of coarse recycled concrete and ceramic aggregates: durability performance. Mater Struct 2009;42:663-75.

[72] Lovato PS, Possan E, Molin DCCD, Masuero ÂB, Ribeiro JLD. Modeling of mechanical properties and durability of recycled aggregate concretes. Constr Build Mater 2012;26:437-47.

[73] Evangelista L, de Brito J. Durability performance of concrete made with fine recycled concrete aggregates. Cem Concr Compos 2010;32:9-14.

[74] Zega CJ, Di Maio A. Use of recycled fine aggregate in concretes with durable requirements. Waste Manage 2011;31:2336-40.
[75] Corinaldesi V, Moriconi G. Influence of mineral additions on the performance of 100\% recycled aggregate concrete. Constr Build Mater 2009;23:2869-76.

[76] Abbas A, Fathifazl G, Isgor O, Razaqpur A, Fournier B, Foo S. Durability of recycled aggregate concrete designed with equivalent mortar volume method. Cem Concr Compos 2009;31:555-63.

[77] Yang H, Deng Z, Li X. Microscopic mechanism study on carbonation resistance of recycled aggregate concrete. Adv Mater Res 2011:1001-6.

[78] Tian F, Hu W, Cheng H, Sun Y. Carbonation depth of recycled aggregate concrete incorporating fly ash. Adv Mater Res 2011;261-263:217-22.

[79] Zhu P, Wang X, Feng J. Carbonation behavior of recycled aggregate concrete under loading. Adv Mater Res 2011;250-253:779-82.

[80] Sim J, Park C. Compressive strength and resistance to chloride ion penetration and carbonation of recycled aggregate concrete with varying amount of fly ash and fine recycled aggregate. Waste Manage 2011;31:2352-60.

81] Shayan A, Xu A. Performance and properties of structural concrete made with recycled concrete aggregate. ACI Mater J 2003:371-80.

[82] Tsujino M, Noguchi T, Tamura M, Kanematsu M, Maruyama I. Application of conventionally recycled coarse aggregate to concrete structure by surface modification treatment. J Adv Concr Technol 2007;5:13-25.

[83] Jianzhuang X, Bin L, Zhang C. Effects of recycled coarse aggregates on the carbonation evolution of concrete. Key Eng Mater 2010;417-418:697-700. 